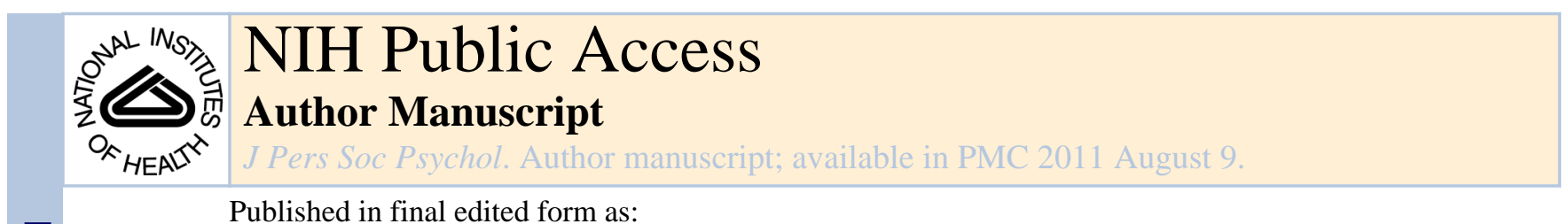

Published in final edited form as:

J Pers Soc Psychol. 2006 March ; 90(3): 351-367. doi:10.1037/0022-3514.90.3.351.

\title{
Construal Levels and Self-Control
}

\author{
Kentaro Fujita, \\ Department of Psychology, New York University
}

Yaacov Trope,

Department of Psychology and Stern Business School Marketing Department, New York

University

Nira Liberman, and

Department of Psychology, Tel Aviv University, Tel Aviv, Israel

Maya Levin-Sagi

Department of Psychology, Tel Aviv University, Tel Aviv, Israel

\begin{abstract}
The authors propose that self-control involves making decisions and behaving in a manner consistent with high-level versus low-level construals of a situation. Activation of high-level construals (which capture global, superordinate, primary features of an event) should lead to greater self-control than activation of low-level construals (which capture local, subordinate, secondary features). In 6 experiments using 3 different techniques, the authors manipulated construal levels and assessed their effects on self-control and underlying psychological processes. High-level construals led to decreased preferences for immediate over delayed outcomes, greater physical endurance, stronger intentions to exert self-control, and less positive evaluations of temptations that undermine self-control. These results support a construal-level analysis of selfcontrol.
\end{abstract}

\section{Keywords}

self-regulation; self-control; mental construal; preference reversals

\begin{abstract}
There has been a resurgence of research on motivation and self-regulation in social psychology (e.g., Gollwitzer \& Bargh, 1996; Heckhausen \& Dweck, 1998; Higgins \& Kruglanski, 2000; Sorrentino \& Higgins, 1986). Researchers in this area have become particularly interested in self-control questions, namely, when and how people fail to do what they want while possessing the knowledge, skill, and opportunity that are required to do what they want (e.g., Baumeister \& Heatherton, 1996; Kivetz \& Simonson, 2002;

Mischel, Shoda, \& Rodriguez, 1989; Wertenbroch, 1998). With implications for education, political science, economics, and clinical and developmental psychology, the importance of studying self-control is widely recognized. However, there is surprisingly less consensus on what self-control is. Extant programs of research have differed in the way they conceptualize what the exertion of self-control entails and how it might be promoted.
\end{abstract}

Baumeister et al. (e.g., Baumeister \& Heatherton, 1996; Muraven \& Baumeister, 2000) have proposed that exerting self-control requires one to inhibit consciously undesired automatic,

Copyright 2006 by the American Psychological Association

Correspondence concerning this article should be addressed to Kentaro Fujita, Department of Psychology, New York University, 6

Washington Place, 7th floor, New York, NY 10003. kf348@nyu.edu. 
routinized reactions. For example, a smoker who decides to quit must consciously fight the habitual urge to light up when among other smoking peers. When individuals monitor their actions consciously and prevent automatic behaviors from being executed, they are said to be exerting self-control. According to this model, any factor that impinges on one's conscious resources would increase self-control failures. A number of other researchers have also suggested similar distinctions between automatic versus controlled psychological processes and behaviors (e.g., Bargh \& Chartrand, 1999; Devine, 1989; Gilbert, Pelham, \& Krull, 1988).

Others (Ainslie \& Haslam, 1992; Thaler, 1991; Trope \& Fishbach, 2000; Wertenbroch, 1998) have suggested that self-control requires one to make decisions and to act in accordance with long-term rather than short-term outcomes. For example, a student preparing for an exam (long-term outcome) should forgo all activities that may be more appealing in the short term, such as going out with friends to party. Self-control in these models is defined as sacrificing short-term outcomes in favor of long-term outcomes.

Factors that draw attention to immediate, near-future outcomes are likely to undermine selfcontrol efforts, whereas those that direct attention to more distant future outcomes are more likely to strengthen self-control efforts.

Mischel et al. (1989; Metcalfe \& Mischel, 1999) have suggested that actions can be instigated by either a "hot system" or a "cool system." The hot system is composed of affective mental representations and, when activated, leads to appetitive, impulsive responses. The cool system is composed of emotionally neutral cognitions that guide behavior in a contemplative, reflective manner. Self-control from this perspective involves preferential activation of the cool system over the hot system. A child waiting out a delay in the presence of a single, immediately available marshmallow to earn an additional marshmallow is more likely to succeed if she thinks of the treat in a cool manner ("It looks like a cloud") rather than a hot manner ("It looks yummy"). When the hot system is activated over the cool system, however, individuals will tend to fail at their self-control efforts. Factors that enhance the activation of the hot system (e.g., attention to the appetitive qualities of a stimulus) will hamper self-control, whereas those that promote the activation of the cool system over the hot system will enhance self-control (e.g., mental transformation of temptations into nonappetitive objects).

Loewenstein (1996) has distinguished between visceral responses and rational self-interest. Self-control involves making decisions and behaving in ways that reflect rational preferences and not visceral reactions (i.e., physiological, biologically based responses to a situation). For example, dieters who are presented with chocolate cake should make decisions based on rational calculations of preferences, not those based on hunger pangs. The impulse to eat the cake originates from one's physiological reaction to food when hungry, which conflicts with any rational decision to not eat the cake. Exerting self-control requires reducing the impact of visceral reactions on one's preferences, decisions, and actions. Factors that increase the physiological arousal (e.g., states of deprivation) should negatively impact self-control, as should those that impair rational decision-making process. Any factors that reduce the impact of visceral reactions should, in contrast, promote selfcontrol.

\section{A Construal Level Analysis of Self-Control}

In the present study, we propose another conceptualization of self-control that integrates previous approaches in a more general theoretical framework and also makes new predictions. We argue that self-control can be broadly conceptualized as making decisions and acting in accordance with global, high-level construal of the situation rather than local, 
low-level construal. Self-control is enhanced when individuals are able to see the proverbial forest beyond the trees. Construal level theory (CLT) posits that the same event or object can be represented at multiple levels (Trope \& Liberman, 2003). High-level construals entail constructing abstract conceptualizations of information about objects and events. They apply to a broad array of examples and selectively include relevant and exclude irrelevant features of those objects and events. High-level construals, therefore, capture the superordinate, central features of an object or event, and abstracting these high-level, immutable features conveys the general meaning of the event. Low-level construals, alternatively, consist of subordinate, incidental features. In low-level construals, events and objects are unique and specific. For example, whereas features such as flashy advertisements and celebrity appearances might specifically identify a particular event ("watching the Olympics") at a low-level construal, conceptualizing the same event at a high-level construal ("enjoying sports") renders such features irrelevant and highlights other features such as quality of the competition.

Research has shown that representations at high and low levels are distinct. For example, the activation of high-level construals leads to categorization in fewer, broader, and abstract units, whereas activation of low levels leads to categorization in multiple, narrow, and concrete units (Liberman, Sagristano, \& Trope, 2002, Study 1). High-level representations are also more coherent and integrative, whereas low-level representations are more specific and disparate (Liberman et al., 2002, Study 4; Nussbaum, Trope, \& Liberman, 2003). Moreover, individuals' judgments, decisions, and behaviors differ as a function of construal level. When high-level construals are activated, more weight is given to high-level features in preferences and actions. When low-level construals are activated, preferences and actions are based increasingly on low-level features. Studies have shown, for example, that, when deciding between tasks that differ in valence of primary and secondary features, individuals at high levels of construal increasingly weight primary features over secondary features in evaluations and preferences (Trope \& Liberman, 2000). Consistent with action identification theory (Vallacher \& Wegner, 1987), the representation of action in terms of means- ends relationships is viewed as an important dimension of level of construal of instrumental actions (see Liberman \& Trope, 1998). However, CLT has been shown to apply to any object or event, not only to instrumental actions. Moreover, levels of construal may differ on dimensions that are unrelated to the means- ends distinction, such as whether they refer to primary versus secondary features of objects. For example, an individual buying a new radio might consider a central feature of the radio, such as its sound quality, or focus on a secondary feature, such as how eye-catching the display of a built-in clock is (see Trope \& Liberman, 2000).

A major determinant of what level of construal is activated is the psychological distance of the event or object in consideration. Distancing a target on any psychological dimension (time, space, social distance, hypotheticality) leads to greater activation of high-level construals rather than low-level construals (Liberman et al., 2002; Liberman, Trope, \& Stephan, in press). The tendency to construe situations at high and low levels can also be procedurally primed (Smith \& Branscombe, 1987), activated by using high-level construals in unrelated prior contexts. Imagining unrelated distant future events, for example, has been shown to enhance thinking more abstractly and generally, whereas imagining unrelated near-future events has been shown to promote more concrete, detailed cognitive processing (Förster, Friedman, \& Liberman, 2004). Research has also demonstrated that the tendency to construe situations at high or low levels can be induced directly through manipulations that activate cognitive procedures or mind-sets associated with each respective construal (Freitas, Gollwitzer, \& Trope, 2004). 
Because the valences of high- and low-level features are independent, the same object can elicit opposing action tendencies, depending on the level of construal activated. In selfcontrol conflicts, when one makes decisions or acts in accordance with the action tendency that is associated with high-level construals, one exerts self-control. In contrast, if one makes decisions or behaves in accordance with the action tendency associated with lowlevel construals, one experiences self-control failure. For example, for a student committed to performing well on final exams, an invitation to attend a party while studying may create a conflict between doing well on final exams (high-level concern that suggests not going to the party) and seeing one's friends (low-level concern that suggests going to the party). Selfcontrol entails putting one's high-level concerns in a particular situation before one's lowlevel concerns, making decisions and acting in a manner that is consistent with high-level construals over low-level construals. It should be noted, however, that what are high- and low-level concerns may change as a function of the situation or individual differences. For example, for a person unconcerned about academics but for whom social relationships are highly valued, seeing one's friends at a party may represent a high-level concern, whereas studying for final exams may represent a low-level concern.

The present research examines a straightforward prediction that follows from this conceptualization of self-control, namely that enhancing the tendency to construe a situation in high-level terms would correspondingly promote decisions and actions that reflect selfcontrol. The activation of high-level construals should cause high-level features to be weighed preferentially in evaluations and decisions (Trope \& Liberman, 2003). In turn, this should lead individuals to make decisions and act in accordance with their primary, central objectives and not secondary, incidental factors. It is important to note that high-level (vs. low-level) construals may be activated without boosting (vs. depleting) processing resources and without activating cool (vs. hot) representations or rational thinking (vs. visceral arousal). Demonstrating the effects of activating construal levels may, therefore, make a novel contribution to extant models of self-control. We are not suggesting, however, that the predicted effects of construal level are inconsistent with previous models. Rather, the proposed construal-level analysis builds on and integrates these other approaches. As discussed in more detail in the General Discussion, the factors proposed by these models tend to be related to construal level. Thus, high-level construals often involve more effortful, deliberate, cool, rational, and long-term thinking. We believe that these factors represent instantiations of a broader, more general model of self-control, a model for which we attempt to provide empirical evidence.

\section{The Present Experiments}

We conducted six experiments to test the hypothesis that activation of high levels of construal would lead to greater self-control than low levels. In the first five experiments, we experimentally induced high or low construal levels by means of procedural priming, that is, by having participants engage in ostensibly unrelated tasks that required using high- or lowlevel construals (i.e., Smith \& Branscombe, 1987). We then observed the carryover effects that these primed construal levels had on subsequent ostensibly unrelated self-control tasks. In the first two experiments, participants considered why versus how they engaged in a given action. Previous studies indicated that asking why one engages in an action activates high-level construals, whereas asking how one engages in an action activates low-levels construals (Freitas et al., 2004; Vallacher \& Wegner, 1987). In Experiments 3a, 3b, and 4, participants generated superordinate categories or subordinate exemplars for various types of objects. Superordinate categorization is a cognitive process associated with high-level construals and thus should activate a tendency to construe at high levels, whereas subordinate categorization is a process linked with, and as such should activate, low-level construals (Liberman et al., 2002). In Experiment 5, we directly manipulated level of 
construal by systematically changing the manner in which various self-control conflicts were described.

We then assessed the effects of these manipulations on various measures of self-control and tested the proposed underlying mechanisms. Our measures included preferences for immediate over delayed outcomes (Experiment 1), physical endurance (Experiment 2), behavioral intentions to undertake activities requiring self-control (Experiment 3), and evaluations of temptations (Experiments 4 and 5). We predicted that high-level construals would lead to decreased preferences for immediate over delayed outcomes, greater physical endurance, stronger behavioral intentions to exert self-control, and less positive evaluations of temptations.

\section{Experiment 1: Priming Levels and Preferences for Immediate Versus Delayed Outcomes}

\section{Overview}

Participants completed an exercise designed to induce a tendency to construe situations at a high or low level. Half of the participants were procedurally primed to use high-level construals by considering questions related to why they engaged in certain actions (abstracting the superordinate concerns motivating a behavior). The others were procedurally primed to use low-level construals by generating answers as to how they accomplished certain actions (specifying the subordinate considerations of implementing a behavior). Previous research has demonstrated that considering questions of why are effective in procedurally priming high-level construals, whereas considering questions of how are effective in procedurally priming low-level construals (Freitas et al., 2004). ${ }^{1}$

As a measure of self-control, participants were presented with several scenarios that described a positive outcome. Participants were asked to indicate how much they would pay to receive that outcome both immediately and delayed in time. The time it takes to receive an outcome should be secondary to the value of the outcome itself, making the outcome itself a positive high-level feature and the delay a negative secondary feature. ${ }^{2} \mathrm{An}$ overemphasis on the secondary issue of time in preferences has been shown to be associated with poor self-control, because it often leads to choices and preferences that favor small immediate rewards over larger delayed rewards (see Ainslie \& Haslam, 1992; Frederick, Loewenstein, \& O'Donoghue, 2002). The greater the difference between immediate versus delayed monetary valuations of the same event, the greater is the tendency for individuals to demonstrate overweighing of the secondary aspect of time. We predicted that those at a high level of construal would demonstrate reduced overweighting of time and hence a decreased preference for immediate over delayed outcomes.

\footnotetext{
${ }^{1}$ Research in our own lab (Agrawal, 2005) has demonstrated the effectiveness of the construal-level manipulation created by Freitas et al. (2004). After completing the manipulation, participants completed the Behavioral Identification Form (BIF; Vallacher \& Wegner, 1989), a personality measure of how abstractly or concretely individuals represent action. The BIF has been shown to reveal differences in construal in past research (Liberman \& Trope, 1998; Study 1). Composed of 25 items, each question requires participants to describe an activity (e.g., "locking a door") by choosing an option that represents the action abstractly ("securing the house") or concretely ("putting a key in a lock"). Demonstrating that the manipulation effectively procedurally primes the tendency to construe unrelated situations at high and low levels of construal, participants in the why condition preferred to construe novel behaviors at high levels of construal compared with those in the how condition.

2 These assumptions do have some empirical basis. Data suggest that waiting for an outcome raises questions about whether and how one will actually receive the outcome and that these issues of probability and feasibility are subordinate concerns to the value of the outcome itself (Keren \& Roelofsma, 1995; Rubenstein, 2001; Sagristano, Trope, \& Liberman, 2002).
} 
Participants-Thirty students (13 women and 17 men) at New York University participated in the study in exchange for course credit. Participants were randomly assigned to condition.

Procedures-Participants were tested in groups of 1 to 4 by a male experimenter unaware of condition. As a cover story, the experimenter told participants that they would be completing materials for two independent studies during the 30-min session.

Construal-level manipulation: Participants first completed a construal-level priming manipulation, developed by Freitas et al. (2004), which was ostensibly described as a survey of student's opinions and activities. Those assigned to the high construal level condition were presented with the question, "Why do I maintain good physical health?" They were then presented with a diagram of vertically aligned boxes that began at the bottom of the page and were connected by upward arrows labeled Why? (see Freitas et al., 2004). The box at the very bottom of the diagram was filled in with the statement, "Maintain good physical health." Participants were instructed to insert a response in the box immediately above the bottom box, answering the question of why they would maintain good physical health. After inserting their first answer, they were to insert a second response in the box immediately above the box they had just completed answering the question why they would engage in their initial response. For example, a participant might have answered the question, "Why do I maintain good physical health?" by writing, "To do well in school." The diagram would then prompt them to ask themselves, "Why do I want to do well in school?" On completing that answer, participants were then prompted again by the diagram to ask themselves why they might engage in their response. Participants provided four responses in this manner.

Those assigned to the low construal level condition were presented with the question, "How do I maintain good physical health?" As with the high construal level condition, participants were then presented with a diagram of vertically aligned boxes. These boxes, however, began at the top of the page and were connected by downward arrows labeled How? The box at the top of the diagram was filled in with the statement, "Maintain good physical health." Participants were instructed to insert a response in the box immediately below the top box, answering the question of how they would maintain good physical health. After providing their first answer, the diagram prompted participants to insert a second response in the box immediately below, asking themselves how they would engage in their initial response. For example, participants might have responded to the question, "How do I maintain good physical health" by writing, "Go exercise." The diagram would then prompt them to ask, "How does one go exercise?" On completing a second response, the diagram would then prompt them again to ask how they would engage in their second response. As with the high-level manipulation, participants provided four responses.

Measurement of preferences for immediate and delayed outcomes: After all participants completed the construal-level manipulation, they were presented with what was ostensibly the second of two independent studies. They read four scenarios that described an item that the participants might buy: a discount gift certificate to a restaurant, a DVD player, a set of four movie passes, and a discount coupon to the university bookstore. Participants indicated the dollar amount that they would pay to receive the item (a) immediately and (b) delayed in time. Half the scenarios (DVD player and movie passes) required participants first to indicate a monetary value for receiving the item immediately and then delayed in time, whereas the other half (restaurant and bookstore) required them first to write down the dollar amount for receiving the item delayed in time and then immediately. The time delay for 
each of the scenarios varied (favorite restaurant, 6 months; DVD player, 1 year; movie, 1 month; bookstore, 1 year), and the presentation order of the scenarios was counterbalanced.

Other questionnaires: Participants were then presented with several demographic questions. They also completed a funneled debriefing form (Bargh \& Chartrand, 2000) to probe for suspicion regarding the experimental manipulations. When all participants had completed the follow-up questionnaires, they were carefully debriefed and dismissed.

\section{Results}

Manipulation Check-As a manipulation check, two judges unaware of condition measured each participant's level of construal based on the abstractness of their responses to the why versus how manipulation (see Hampson, John, \& Goldberg, 1986; Liberman \& Trope, 1998). If a response fit the criterion $Y$ by $X$, where $X$ was the participant's response to prompt $Y$ (i.e., participants' responses were a subordinate means to the original statement "maintain good physical health"), judges coded the response with a score of -1 . If a response fit the criterion $X$ by $Y$ (i.e., participants' responses were a superordinate end served by maintaining good physical health), judges coded the response with a score of +1 . If a participant's response fit neither criterion, the response was coded as 0 . Ratings of each participant's four responses were then summed to create an index of level of construal with a potential range of -4 to +4 ; higher scores indicate higher levels of construal. The ratings by the two judges were highly correlated $(r=.91)$ and were averaged together. As expected, participants exposed to why questions $(M=2.97)$ generated responses that reflected higher levels of construal compared with those exposed to how questions $(M=-3.27), t(28)=$ $16.58, p<.001, r=.95$.

Preferences for Immediate Versus Delayed Outcomes-We computed difference scores by subtracting the dollar value that participants were willing to pay for the distant future versions of each of the four scenarios from the amount they were willing to pay for the immediate versions. Larger differences scores indicate stronger preferences for immediate over delayed rewards and hence a lack of self-control. These difference scores were normally distributed and were analyzed with a 2 (construal level: high vs. low) $\times 4$ (scenario: restaurant, DVD player, movie, bookstore) multivariate analysis of variance (MANOVA). As predicted, there was a main effect of level, $F(4,24)=2.96, p=.04, r=.33$. Participants primed to high-level construals demonstrated preferred immediate over delayed outcomes less $(M=35.0, S D=21.0)$ than those primed to low-level construals $(M=45.3$, $S D=20.1){ }^{3}$ The scenario-specific data patterns in raw dollar amounts are presented in Figure 1 . These data indicate that participants exposed to why questions compared with how questions displayed a reduced tendency to value immediate over delayed outcomes. This suggests that high-level construals lead to greater self-control than low-level construals.

\section{Discussion}

Experiment 1 provided preliminary evidence to support the hypothesis that high levels of construal lead to greater self-control than low levels. Participants who answered questions of why they engaged in actions displayed a reduced tendency to prefer immediate over delayed outcomes compared with those who responded to questions of how they engaged in actions.

That is, time delay had less of an impact on those individuals primed to a high-level versus a

\footnotetext{
${ }^{3}$ It would be amiss not to note that the results from one of the scenarios, namely that of purchasing a DVD player, did not demonstrate the same pattern as the others. Univariate analyses on the difference scores revealed that, whereas the effect of condition was significant for the book, $F(1,27)=7.50, p=.01, r=.47$, and movie, $F(1,27)=6.17, p=.02, r=.43$, scenarios and marginally significant for the restaurant scenario, $F(1,27)=3.47, p=.07, r=.34$, it was not significant for the DVD player scenario, $F(1,27)=$. $48, p=.50, r=.13$. The DVD player as an electronic product may be characterized by a steeper depreciation rate compared with the other products. Speculatively, time may be a more primary issue with that particular item, reducing the effect of construal level.
} 
low-level construal. This provides initial evidence that levels of construal can moderate how people make decisions when faced with a self-control dilemma. Through a decreased preference for immediate over delayed outcomes, those at high levels demonstrated a greater tendency to make decisions reflecting self-control than did those at low levels.

It is notable that, although we used an induction that differentially focused participants on subordinate means versus superordinate ends (by having them consider questions of how vs. why), this manipulation of construal levels exerted an effect on subsequent judgments that did not involve a means-end conflict. That is, preferences for immediate versus delayed outcomes do not capture a conflict between means and ends but rather a conflict between what is primary and what is secondary. This suggests that the effect of construal levels on self-control judgments is brought about by a broad change in the level of mental representation or construal that cannot be reduced to changes in whether an action is identified in terms of means or ends (Vallacher \& Wegner, 1987).

Although Experiment 1 indicated that high levels of construal lead to judgments that reflected greater self-control, these judgments were made about hypothetical events. In Experiment 2, we sought to illustrate the effect of construal levels on actual behavior. Demonstrating behaviorally that high levels, versus low levels, lead to greater self-control would provide more compelling evidence that construal levels influence the resolution of self-control conflicts.

\section{Experiment 2: Priming Levels and Physical Endurance}

\section{Overview}

We induced high and low construal levels using the same manipulation as in Experiment 1. To measure subsequent self-control, we had participants hold a handgrip, an exercise tool used to strengthen forearm muscles. The duration one can hold the handles of the handgrip closed has been shown to be sensitive to changes in self-control because it causes increasing discomfort and taxes physical endurance (Muraven, Tice, \& Baumeister, 1998). We had participants hold a handgrip ostensibly to receive self-relevant information and told them that the longer they squeezed it, the more accurate the feedback from this assessment would be. Thus, participants had to choose between receiving increasingly accurate self-relevant feedback (high-level feature) and relieving the discomfort of their hand (low-level feature). We predicted that high-level construals would lead participants to grip the handgrip longer than low-level construals, thereby leading to greater physical endurance and self-control.

Method

Participants-Thirty-nine students (27 women, 11 men, 1 unreported) at New York University participated in the study in exchange for course credit. Participants were randomly assigned to condition.

Procedures-Participants were tested individually by a female experimenter unaware of condition. As a cover story, participants were told that they were participating in a psychophysiological study of personality. Before starting, however, they were asked to perform a baseline measurement.

Baseline measurement: The experimenter presented the participants with a handgrip and asked them to grip it as long as possible. To ensure precise timing, the experimenter had participants place a marble between the handles. When the marble fell from the handles, the experimenter knew that participant had released the handgrip. Participants were instructed not to lean their elbows or arms against the chair or desk and to hold the handgrip with their 
dominant hand. The experimenter then timed how long participants were able to hold the handgrip closed using a stopwatch. This recorded time served as a premanipulation measurement (to adjust for individual differences in arm strength) by which to compare the effects of the construal-level manipulation.

Construal-level manipulation: After measuring the baseline duration participants were able to squeeze the handgrip, the experimenter presented, as an unrelated student survey, the same construal-level manipulation as in Experiment 1. To avoid any inadvertent contamination of the measurement of physical endurance, however, we changed the topic participants considered. Rather than asking participants, "Why do I maintain good physical health?" and "How do I maintain good physical health," we had them deliberate, "Why do I maintain good personal relationships?" and "How do I maintain good personal relationships?" The materials were identical in all other respects.

Handgrip task: When finished, participants were prepared for the psychophysiological task. They were told that a new psychophysiological measure had been developed that measured the activation of their sensory-motor system and that this information could be used as a valid, highly diagnostic personality measure. They were further informed that they would receive feedback from this assessment at the end of the experimental session.

The experimenter attached dummy electrodes to the participants' dominant arm and handed them the handgrip and marble. She explained that gripping the handgrip would activate their sensory-motor systems, which would be measured by the electrodes. Because the measurements were somewhat unreliable, however, participants were told that multiple measurements were necessary to obtain an accurate reading. Participants were told that, although holding the handgrip was uncomfortable, the longer they held the handgrip, the more accurate the personality information to be provided at end of the experimental session would be.

As with the baseline measurement, participants were asked to place the marble between the handles of the handgrip. While measuring the signals on the computer to which the electrodes were attached, the experimenter surreptitiously timed how long participants gripped the handgrip using a computerized timer. When the marble fell from the handles, the experimenter stopped the timer and removed the electrodes from the participants' arms.

Other measures: Participants then completed the Positive and Negative Affect Scales (PANAS; Watson, Clark, \& Tellegen, 1988) to address the potential confound of mood in this study. They also completed several demographic items and a funneled debriefing questionnaire designed to probe for suspicion regarding the cover story and experimental manipulations (Bargh \& Chartrand, 2000). When finished, participants were carefully debriefed and dismissed.

\section{Results}

Manipulation Check-As in Experiment 1, as a manipulation check, two judges unaware of condition analyzed each participant's level of construal based on the abstractness of their responses to the why versus how manipulation. The ratings by the two judges were highly correlated $(r=.94)$ and were averaged together. As expected, those who generated responses to why they engaged in actions $(M=3.19)$ generated responses that reflected higher levels of construal than those who generated responses to how they engaged in actions $(M=$ $-3.39), t(38)=17.69, p<.001, r=.94$. 
Handgrip Measurements-To adjust for individual differences in arm strength, we first calculated difference scores by subtracting the baseline handgrip measurement from the psychophysiological handgrip measurement. This difference score measured the change in physical endurance as a function of the construal-level manipulation. Analysis of these scores showed that participants primed to a high level of construal held the handgrip longer than those primed to a low level of construal, $t(37)=2.14, p=.04, r=.33$. On average, those primed to high-level construals held the handgrip $11.1 \mathrm{~s}(S D=18.9)$ longer than baseline, $t(19)=2.62, p=.02, r=.52$, whereas those primed to low-level construals held the handgrip $4.9 \mathrm{~s}(S D=26.7)$ shorter compared with baseline, $t(18)=0.78, p=.45, r=.18 .{ }^{4}$ As predicted, then, high levels of construal appear to lead to greater physical endurance than low levels of construal.

We analyzed responses to the PANAS to account for potential effects related to mood. One might suggest, for example, that the why versus how manipulation induced different mood states and that these mood states then led to differences in self-control. Contrary to this suggestion, there were no significant differences in positive mood, $t(37)=1.15, p=.26, r=$. 19 , or negative mood, $t(37)=0.74, p=.16, r=.12$. Neither positive mood nor negative mood was significantly correlated with change in physical endurance. Moreover, the effect of level on physical endurance was still significant after statistically adjusting for positive mood, $F(1,36)=4.78, p=.04, r=.34$, and negative mood, $F(1,36)=4.28, p=.05, r=.33$, as a covariate in our analyses. Thus, the effect of level of construal on physical endurance does not appear to be mediated by mood.

\section{Discussion}

The results of Experiment 2 provided a behavioral replication of the results of Experiment 1. Participants procedurally primed to use high-level construals displayed greater physical endurance than those primed to use low-level construals. That is, those who considered why they maintain good relationships in a prior task held a handgrip closed longer than those who considered how they maintain good relationships. This suggests that high-level construals do indeed lead to greater self-control. This effect was not mediated by mood. These results extend those of Experiment 1 by demonstrating that construal levels influence not only judgments and evaluations of hypothetical events but also one's actual exertion of self-control.

Not only did participants exposed to why questions hold the handgrip longer than those exposed to how questions, but they also held it significantly longer than their original baseline measurement. One might have expected that, having held the handgrip once before, the same hand would be fatigued while trying to hold the handgrip a second time. That participants primed to a high level of construal held the handgrip for a longer duration the second time may indicate that the manipulation led to an increase of self-control above and beyond what it had been during the baseline measurement. Those primed to a low level of construal, in contrast, released the handgrip after about the same duration or sooner compared with baseline despite the additional motivation of receiving accurate self-relevant diagnostic feedback.

\footnotetext{
${ }^{4}$ As noted elsewhere in the text, previous research has indicated that prior exertions of self-control lead to impairments in self-control, or ego depletion, on subsequent tasks (Muraven \& Baumeister, 2000). One might be surprised that participants at low levels of construal did not show a decrement in physical endurance, particularly because they exerted self-control for the baseline measurement. Our results, however, mirror previous research that has indicated that a baseline measurement for the handgrip task does not cause significant ego depletion (Muraven et al., 1998, Study 1). Speculatively, it may be that ego-depletion patterns are more evident when comparing self-control across tasks of different domains than those of the same domain. In this case, however, it may also be that the added motivation of receiving accurate personality feedback negated any ego-depletion effects (Muraven \& Slessareva, 2003).
} 
Although Experiments 1 and 2 provided evidence that high levels of construal affect judgment and behaviors relevant to self-control conflicts, both studies used the same manipulation of construal level, namely considering questions of why versus how. Inducing differences in levels of construal using another manipulation could address any potential confounds and demonstrate the robustness of the effect. Moreover, the first two experiments did not demonstrate whether the effects of construal level acted specifically on self-control or on some other more general psychological process. For example, it is possible that high levels of construal make individuals more compliant or distractible, induce greater cognitive load, or enhance generalized motivation and that these more general effects influence selfcontrol decisions and actions. If construal levels exert their effect uniquely on self-control by shifting the weight of high- and low-level features in decisions and actions, they should have no effect in situations that do not involve a self-control conflict. That is, the effects of priming construal level should be apparent only when attaining valued benefits at the high level is associated with costs at the low level. Demonstrating the specificity of the effects of high and low levels by testing this boundary condition would provide evidence for the proposed process by which high levels of construal lead to greater self-control and help rule out a number of alternate process explanations.

Experiments $3 \mathrm{a}$ and $3 \mathrm{~b}$ were designed to address these issues. In Experiment 3a, we validated a new method of procedurally priming levels of construal. Rather than having participants generate reasons why they engaged in some activity versus how they performed some activity, we asked them to generate category labels (high-level construals) or exemplars (low-level construals) for a number of objects. As mentioned, superordinate categorization is a cognitive process associated with high-level construals, whereas subordinate categorization is associated with low-level construals (Liberman et al., 2002). Engaging in each of these two types of psychological processes should, therefore, procedurally prime high- and low-level construals. In Experiment 3b, we examined the effect of this manipulation on self-control. We also manipulated whether or not participants were exposed to situations in which there was a conflict between costs and valued benefits and in which there was no conflict. In this way, we could systematically compare the effects of priming construal levels in situations involving self-control versus not.

\section{Experiment 3: Priming Levels, Conflicts, and Intentions}

\section{Overview}

Participants completed an exercise in which they were asked to generate superordinate category labels (high-level construals) or subordinate exemplars (low-level construals) for a variety of common objects. To validate this new experimental manipulation of construal levels, in Experiment 3a we presented participants with written descriptions of a series of situations. For each situation, participants were asked to choose between two redescriptions of the event: One emphasized global, high-level concerns involved in the situation and the other highlighted specific, low-level actions performed in the situation. We predicted that individuals at high levels of construal would prefer the former to the latter compared with those at low-level construals, suggesting that they have an increased tendency to represent events in reference to their high-level concerns and motives.

To test the effects of this new procedural priming on self-control, participants in Experiment $3 \mathrm{~b}$ completed the same manipulation but were presented with descriptions of four psychological studies. All four studies were described in a manner that suggested a highlevel benefit for participating (i.e., receive self-relevant information). Two of the studies, however, were described in a manner that suggested that they involved low-level costs (e.g., painful or challenging procedures), suggesting that participation involved self-control conflicts between high-level benefits and low-level costs. The other two had no costs for 
participating and, therefore, involved no self-control conflicts (only high-level benefits). ${ }^{5}$ Participants indicated how much they would like to participate in each study. Because costbenefit conflicts represent self-control dilemmas only when the high-level benefits are valued, however, we also measured how much each participant valued the benefits of each study. We predicted that high-level construals compared with low-level construals would lead to stronger behavioral intentions to participate but only in studies that involve conflicts between costs and valued benefits. There should be no effect of construal level when there are no costs or when the high-level benefits are not valued.

\section{Method}

Participants-Forty-four students (18 women, 26 men) at New York University participated in Experiment 3a in exchange for course credit or were paid $\$ 10$. Fifty-five students (34 women, 19 men, 2 unreported) from the same pool participated in Experiment 3b. Participants were randomly assigned to condition.

Procedures-Participants were tested in groups of 1 to 5 by one of two female experimenters who were unaware of condition. The experimenter distributed a packet of papers to each participant that contained all of the experimental materials. Participants were instructed to read carefully the directions for each task and to complete the forms in the order that they were presented.

Construal-level manipulation: Participants in both Experiments $3 \mathrm{a}$ and $3 \mathrm{~b}$ first completed a manipulation of construal level. Participants were presented with 40 words, such as singer, king, pasta, bag, and soap, which were printed two to a page. Those in a high-level construal were instructed to generate superordinate category labels by answering the question, “_ _ is an example of what?" Those in the category condition were instructed to generate subordinate exemplars by answering the question, "An example of is what?"

Global concerns (Experiment 3a): Participants in Experiment 3a only were then presented with eight one-sentence descriptions of various situations (e.g., recycling). Each description was followed by two alternate descriptions of the event. One referred to global, high-level concerns or motives in the situation (e.g., "caring for the environment"), whereas the other specified a concrete, low-level action (e.g., "bagging paper, glass, and cans"). Participants were asked to choose which of the two alternate statements best described the original situation. A complete list of items is presented in Appendix A.

Behavioral intentions (Experiment 3b): Participants in Experiment 3b were presented with descriptions of four psychological studies immediately after the category label or exemplar task. Participants were informed that they would be participating in one of these later in the experimental session. To acquaint participants with the procedures of each study, they were provided with descriptions that enumerated benefits and risks for participating.

All four studies (described as related to the areas of health psychology, cognitive psychology, relationships, and industrial-workplace psychology) were presented with positive high-level benefits for the participant. For example, the description of a health psychology study stated that participants would receive a diagnostic assessment of their risk of heart disease. In addition to the benefits, to manipulate whether or not a situation involved self-control conflicts, half of the psychological studies were presented with low-level costs, described as risks, whereas the others were presented with no costs. The costly version of

\footnotetext{
${ }^{5}$ Supporting the notion that only situations with high-level gains matched with low-level costs represent self-control conflicts for individuals is research by Trope and Fishbach (2000) showing that people plan and initiate strategies to increase the likelihood of success in self-control efforts only when there are short-term costs of pursuing long-term benefits.
} 
participating in the health psychology study, for example, suggested that the assessment procedures were arduous and painful. The no-cost version of the health psychology experiment, in contrast, stated that there were no risks involved in the procedures and that participants found them easy and completely painless. Descriptions of the materials used in all four studies are presented in Appendix B. The presentation order of each of the study descriptions was counterbalanced. Whether or not a study was presented with costs or not was randomized, with the constraint that each participant was presented with two cost and two no-cost study descriptions.

After presentation of each experiment, two items were introduced, designed to measure participants' behavioral intentions in participating in each study. The two items asked, "How interested are you in participating in this study?" and "How willing are you to participate in this study?" Participants responded using a 9-point Likert scale $(1=$ not at all, $9=$ extremely). A single item also assessed the value each participant placed on the high-level benefits for each study. For instance, for the health psychology study, participants were asked, "How important is it for you to be physically healthy?" Participants responded to these benefit importance questions using a 9-point Likert scale $(1=$ not important at all, $9=$ extremely important). The items used in the other study descriptions are presented in Appendix B.

Other measures: After completing their respective measures, participants in both Experiments $3 \mathrm{a}$ and $3 \mathrm{~b}$ were then asked to complete the PANAS to account for any potential differences between conditions with positive and negative mood states. To address the potential confound of ego depletion, participants in Experiment 3a were asked how much self-control they felt right now and how much willpower they felt right now $(\alpha=.86, r=$. 77; Muraven \& Slessareva, 2003; Muraven et al., 1998). Those in Experiment $3 \mathrm{~b}$ were asked how difficult they thought the category versus exemplar task was and how much effort they put into it (Muraven et al., 1998). Participants were asked to answer these using a 9-point Likert-type scale $(1=$ not at all, $9=$ extremely). They then completed a funneled debriefing designed to probe for suspicion regarding the cover story and experimental manipulations (Bargh \& Chartrand, 2000). When all participants completed the experimental materials, they were carefully debriefed and dismissed.

\section{Results}

Manipulation Check-As a manipulation check, two judges unaware of condition analyzed each participant's level of construal based on the abstractness of their responses to the category versus exemplar task. If a response fit the criterion "[participant's response] is an example of [target word]," judges coded the response with a score of -1 . If a response fit the criterion "[target word] is an example of [participant's response]," judges coded the response with a score of +1 . If a participant's response fit neither criterion, the response was coded as 0 . Scores of all 40 items were then summed to create an index of level of construal, with a potential range of -40 to +40 ; higher scores indicate higher construal levels. The ratings by the two judges were highly correlated $(r=.99)$ and were averaged together to create a single index of abstractness. As predicted, participants who generated category labels had significantly more abstract responses than those at a low level both in Experiment $3 \mathrm{a}(M=33.3$ vs. $M=-34.9$, respectively $), t(42)=39.51, p<.001, r=.99$, and Experiment $3 \mathrm{~b}(M=32.8$ vs. $M=-37.6$, respectively $), t(53)=40.56, p<.001, r=.98$.

Global Concerns (Experiment 3a)-There was no effect of experimenter, item order, or whether the participant was paid or received course credit in either of the two studies. All subsequent analyses were performed collapsing across these variables. To create an index of participants' alternate description preferences in Experiment 3a, for each item we assigned a 
value of 0 when participants preferred the low-level action description and a value of 1 when they preferred the high-level concern description. These codes were then summed to create a single scale ranging from 0 to 8 ; larger values indicate stronger preferences for the global concern descriptions. Providing validating support for the experimental manipulation, participants who were induced into high levels of construal by generating category labels in a previous unrelated task preferred descriptions of situations that emphasized high-level concerns and motives $(M=4.30, S D=.92)$ compared with those induced into low levels of construal by generating exemplars $(M=3.58, S D=1.28), t(42)=2.09, p=.04, r=.31$.

Behavioral Intentions (Experiment 3b)-In Experiment 3b, to create an index of the participants' behavioral intentions to participate in each of the four studies, we averaged participants' ratings of how interested they were in participating in the study and how willing they were to participate in the study. The reliabilities between these two items were high for each of the four studies ( $\alpha \mathrm{s}=.90-.94, r \mathrm{~s}=.81-.89)$. There were no significant differences by condition on the benefit value question for each scenario, $F(3,53)=.05, p=$. $83, r=.03$, suggesting that it is acceptable to use them as predictor variables.

To take full advantage of the within-subjects nature of two of our independent variables (presence vs. absence of low-level costs and the value of the high-level benefits for each study), we used multilevel modeling techniques to model our data. That is, aggregating across all four study descriptions, we regressed participants' behavioral intentions to participate on level of construal (high vs. low), whether a study scenario was presented with low-level costs (no costs vs. costs), and how valued the high-level benefits of each study were (continuous). The latter two variables were entered as within-subjects variables (Level 1 variables), and level of construal was entered as a between-subjects variable (Level 2 variable). All indicator variables were contrast coded and continuous variables centered. We statistically adjusted for the unique effects of each study description.

The results revealed the predicted three-way interaction among level, costs, and benefit value, $\gamma=1.44, S E=0.46, t(53)=3.16, p=.003$. The nature of this three-way interaction is graphed in Figure 2; behavioral intentions are plotted for points $1 S D$ above and below the mean benefit value rating (Cohen, Cohen, West, \& Aiken, 2003). The independent effects of level, costs, and benefit value were not significant, supporting our prediction that levels of construal affect self-control only when there is a conflict between costs and valued benefits. However, there was a significant two-way interaction between level and costs, $\gamma=-10.81$, $S E=3.32, t(53)=3.26, p=.002$. When there were no costs, level of construal had no significant effects on behavioral intentions. When scenarios were presented with costs, in contrast, the effect of level was significant, $\gamma=-7.34, S E=2.53, t(53)=2.90, p=.005$. Although these results suggest that high-level construals led to weaker intentions in the presence of costs, this effect was moderated by the value of the high-level benefits (i.e., there was significant interaction between level and benefit value within the high cost condition), $\gamma=1.18, S E=0.33, t(53)=3.54, p<.001$. As predicted, when the high-level benefits were valued, high-level construals led to stronger behavioral intentions than low levels of construal in the presence of costs, $\gamma=3.23, S E=0.87, t(53)=3.73, p<.001$. In contrast, when these same benefits were not valued, there were no differences between high and low construal levels.

The apparent weakening of intentions by those at the high level in the presence of costs can be attributed to a significant two-way interaction between costs and benefit value among those at the high level, $\gamma=0.87, S E=0.28, t(53)=3.14, p<.01$. Among participants at the high level, there were no significant differences in the strength of behavioral intentions when there were no costs. In the presence of costs, those who valued the high-level benefits maintained their intentions, whereas those who did not dramatically weakened their 
intentions. That is, high-level construals not only uphold an individual's intentions in the face of costs when the high-level benefits are important, but they also weaken intentions when benefits are not valued. This two-way interaction was not significant among those at the low level of construal.

Other Measures-We analyzed responses to the PANAS scales to test the viability of mood as an alternate explanation. In Experiment 3a, there were no significant differences in positive mood, $t(42)=1.50, p=.14, r=.23$, or negative mood, $t(42)=0.12, p=.85, r=.03$. Moreover, neither of these variables was significantly correlated with preferences for the high-level concern descriptions. Similarly, in Experiment 3b, there were no significant differences in either positive mood, $t(53)=0.43, p=.67, r=.06$, or negative mood, $t(53)=$ $0.20, p=.84, r=.03$. Negative mood was significantly correlated with behavioral intentions to participate in one of the four studies (cognitive-personality psychology study, $r=.29, p$ $=.03$ ) but not the other three. Positive mood was not significantly correlated with behavioral intentions. Statistically adjusting for both positive and negative mood did not change the pattern of results described previously for either study. Therefore, the effects of the experimental manipulations on the activation of high concerns (Experiment 3a) and behavioral intentions (Experiment $3 b$ ) do not appear to be mediated by mood.

Ego depletion is a state of reduced willpower as a result of prior exertion of self-control (see Muraven \& Baumeister, 2000). One might suggest that generating exemplars taxes one's self-control resources to a greater extent than generating category labels, thus leading to diminished self-control and subsequently weaker intentions to engage in tasks involving self-control. To address this issue, we analyzed responses to the ego-depletion items in Experiments $3 \mathrm{a}$ and $3 \mathrm{~b}$, respectively. There were no significant differences in how much willpower and self-control participants reported after completing the experimental manipulation in Experiment 3a, $t(42)=0.32, p=.75, r=.05$. There were also no significant differences in reported difficulty, $t(53)=0.60, p=.55, r=.08$, nor in effort exerted, $t(53)=$ $0.13, p=.89, r=.02$, in Experiment $3 \mathrm{~b}$. These measures were not significantly correlated with the activation of global concerns (Experiment 3a) nor with the strength of behavioral intentions (Experiment 3b), and statistically adjusting for these factors did not change the pattern of results reported previously. As with mood, an alternate explanation based on an ego-depletion account does not appear tenable. ${ }^{6}$

\section{Discussion}

Validating our manipulation of construal levels, generating category labels in a prior unrelated task led individuals in Experiment $3 \mathrm{a}$ to represent and understand situations in relation to their high-level concerns to a greater extent than generating exemplars. That is, participants procedurally primed to high-level construals preferred to describe subsequent situations by referencing their high-level motives rather than by specifying particular behaviors compared with those primed to low levels. This effect was not mediated by mood or ego depletion. This suggests that generating category labels versus exemplars does effectively manipulate the tendency to construe events at high- and low-level construals, respectively.

Using this new manipulation of construal level, Experiment $3 b$ conceptually replicated Experiments 1 and 2 by showing that those who generated category labels (high-level construal) in a prior task formed stronger subsequent behavioral intentions to undertake activities requiring self-control than those who generated exemplars (low-level construal).

\footnotetext{
${ }^{6}$ One might suggest that self-reports of willpower and self-control might not be sensitive measures of ego depletion. We based our items, however, on those used by ego-depletion researchers as manipulation checks (e.g., Muraven \& Slessareva, 2003; Muraven et al., 1998). In those studies, these items were found to be sensitive to differences in ego depletion.
} 
Moreover, this effect was not mediated by mood or ego depletion. Experiment $3 \mathrm{~b}$ demonstrated the specificity of the effect of construal levels. Construal levels had an effect on behavioral intentions only when a situation involved a self-control conflict (i.e., only when the situation required enduring low-level costs for valued high-level gains). Moreover, high-level construals facilitated overcoming the influence of costs only when the high-level benefits were valued. The specificity of the effects of construal levels on self-control provides support for a model of self-control wherein self-control involves weighting highlevel construals over low-level construals in decisions and actions. They also argue against alternate interpretations of the data such as distraction, compliance, and enhanced generalized motivation. These would all predict a main effect of levels of construal, one that generalizes across all situations, including those that do not involve self-control conflicts.

It is worth noting that when individuals did not value the benefit of receiving self-relevant feedback in Experiment 3b, those at a high-level construal demonstrated a dramatic weakening of intentions when a study was described as involving costs compared with no costs. This weakening of intentions was significantly greater for those at a high-level construal than those at a low-level construal. It seems, then, that in addition to maintaining intentions in the face of costs when an individual values the high-level features of a situation, high-level construals also weaken intentions when the same features are not valued. This provides further evidence that high-level construals lead to structured choices in self-control conflicts that weigh individuals' primary, central considerations above secondary, peripheral concerns.

If it is true that high-level construals enhance self-control by weighting high-level concerns over low-level concerns in evaluation, decision making, and action, then temptations that undermine or subvert these concerns should be evaluated less positively at high levels compared with low levels of construal. In Experiment 4, we tested this hypothesis. As in Experiment $3 b$, however, the effects of construal levels should be specific to self-control conflicts. Construal levels should only influence evaluations of temptations, not nontemptations. Similarly, the effect of construal levels on evaluations should be apparent only among those for whom the temptations might undermine valued goals.

\section{Experiment 4: Priming Levels and Evaluations of Temptations}

\section{Overview}

Participants were experimentally induced into high and low levels of construal using the same procedures as in Experiments $3 \mathrm{a}$ and $3 \mathrm{~b}$ (generating category labels vs. exemplars). They were then presented with a series of words to evaluate. Among these were words commonly associated with temptations that undermine the goal to study. We also asked participants to report how important the goal to study was to them. We predicted that participants primed to high levels of construal would report less positive evaluations of temptations, whereas we expected no differences between conditions in evaluations of nontemptation words. Moreover, we anticipated that this effect would be evident only among those individuals for whom the temptations elicit self-control conflicts (i.e., those who value the goal to study).

\section{Method}

Participants-One hundred fourteen (86 women and 28 men) at New York University participated in the study in exchange for course credit. Participants were randomly assigned to condition. 
Materials and Procedures-Participants were tested in groups of 1 to 6 by one of two female experimenters unaware of condition. The experimenter distributed a packet of papers to each participant that contained all of the experimental materials.

Construal-level manipulation: Using identical procedures as in Experiment 3, participants were asked to generate category labels (high-level) or exemplars (low-level) for 40 common objects.

Evaluations of temptations: Participants were then presented with a list of 40 words (listed in Appendix C). Embedded within these words were 10 words associated with temptations that undermine the goal to study: beer, drinking, e-mail, internet, movie, partying, phone, socializing, television, and video games. These words were taken from previous research on self-control by Fishbach (2006). The other 30 words consisted equally of affectively positive, negative, and neutral words (Bradley \& Lang, 1999). Two orders for item presentation were created by randomly selecting items with the restriction that no temptation word directly preceded or followed another temptation word. For each word, participants were asked to indicate how positive or negative the word was to them at that moment using two unipolar scales $(1=$ not at all positive/negative, and $9=$ extremely positive/negative $)$.

Other measures: Participants were then asked to complete the PANAS mood scale to account for any possible mood differences between the two conditions. They were also asked to answer some demographics items and completed a funneled debriefing designed to probe for suspicion regarding the experimental manipulations (Bargh \& Chartrand, 2000). Participants were also asked to answer four items designed to measure how much they valued the goal to study: "How important is it for you to do well in school?" "How important is it for you to find time to study?" "How committed are you to studying daily?" "How helpful or instrumental do you think studying is to getting good grades?" Participants responded to these items using a 9-point Likert-type scale $(1=$ not at all, and $9=$ extremely $)$. When all participants completed the experimental materials, they were carefully debriefed and dismissed.

\section{Results}

Manipulation Check-As in Experiments 3a and 3b, to measure the success of manipulating levels of construal, two judges unaware of condition rated the abstractness of participants' responses to the category versus exemplar task. The ratings of the two judges were highly correlated $(r=.99)$, and were averaged together to create a single index of abstractness. As predicted, participants who generated category labels $(M=32.0)$ had significantly more abstract responses than those at a low level $(M=-34.9), t(112)=22.56, p$ $<.001, r=.91$.

Evaluations-There were no effects of experimenter or item presentation order, so all subsequent analyses were performed collapsing across these variables. The positive and negative unipolar rating scales were negatively correlated $(r=-.30)$, so we created a single index by subtracting the negative evaluation ratings from the positive evaluation ratings. Higher scores on this index indicate more positive evaluations. We created separate index scores for temptation and nontemptation words by averaging the appropriate ratings. Analysis of the four goal importance items revealed that their reliability was adequate ( $\alpha=$. 79 ; interitem $r=.31-.74)$. These items were averaged to create a single index of how valued the goal to study was to each participant. There were no significant differences by construal level on how valued the goal to study was, $t(112)=0.48, p=.64, r=.07$, indicating that it is acceptable to use goal value as a predictor variable. 
The data were then analyzed using multilevel modeling. We regressed participants' evaluations of the target words on level (high vs. low), goal value (continuous), and word type (temptation vs. nontemptation). Level and goal value were entered as between-subjects variables (Level 2 variables), whereas word type was entered as a within-subjects variable (Level 1 variable). All indicator variables were contrast coded, and continuous variables were centered.

In general, participants evaluated temptation words more positively than nontemptation words, $\gamma=-2.57, S E=0.16, t(109)=19.42, p<.0001$. There was, however, a significant interaction among level, goal value, and word type, $\gamma=0.69, S E=0.27, t(109)=2.56, p=$. 01 . This three-way interaction is graphed in Figure 3; evaluations are plotted for points $1 S D$ above and below the mean goal value (Cohen et al., 2003). As predicted, there were no significant effects or interactions in the evaluations of nontemptations. In contrast, among temptation words, there was a significant effect of level, such that individuals primed to high-level construals tended to evaluate temptations less positively than those primed to low-level construals, $\gamma=-0.48, S E=0.24, t(109)=1.99, p=.05$. As anticipated, however, this effect was qualified by a significant interaction between level and goal value within the evaluation of temptations, $\gamma=-0.62, S E=0.21, t(109)=2.97, p=.004$. There was no effect of level on the evaluation of temptations when the goal to study was not valued, $\gamma=0.24, S E$ $=0.34, t(109)=.71, p=.48$. When the goal to study was valued, however, high-level construals led to significantly less positive evaluations of temptations, $\gamma=-1.20, S E=0.35$, $t(109)=3.50, p<.001$.

As in the previous studies, we analyzed responses to the PANAS scales to test the viability of mood as an alternate explanation. There were no significant differences in positive, $t(112)$ $=0.26, p=.79, r=.02$, or negative, $t(112)=0.98, p=.33, r=.09$, mood between levels of construal. Neither positive nor negative mood was significantly correlated with evaluations of temptations and nontemptations. Statistically adjusting for mood did not change the pattern of results described previously. The effect of construal levels on the evaluation of temptations appears not to be mediated by mood.

\section{Discussion}

The results of Experiment 4 provide additional evidence for the process by which high levels of construal lead to greater self-control. High-level construals are postulated to promote self-control by weighting high-level concerns over low-level concerns in evaluations and decisions. Temptations, which by a construal-level analysis correspond to low-level considerations, should be evaluated less positively in light of high-level concerns. Supporting this proposed process, high levels of construal in Experiment 5 led to less positive evaluations of words associated with temptations that threaten to undermine the goal to study.

Replicating the results of Experiment 3b, the effect of construal levels was apparent only in situations that represented self-control conflicts. Levels of construal only influenced the evaluation of words associated with temptations to the goal of studying. Changing the level of construal by which participants considered non-temptations did not affect evaluations. Moreover, high levels of construal led to less positive evaluations of temptations only among those who valued the goal to study. The specificity of these effects conceptually replicates the results of Experiment $3 \mathrm{~b}$ and provides additional support for a construal level analysis of self-control. Again, as in Experiment 3b, this particular pattern of results also suggests that the effect of levels of construal cannot be reduced to enhanced distractibility, cognitive load, or generalized motivation. These alternate explanations predict an effect of construal that should generalize to all situations, not just self-control conflicts, and cannot by themselves explain the specific pattern of results actually obtained. Furthermore, the results 
from this study indicate that levels of construal exert an effect not only on self-control dilemmas that involve trade-offs between means and ends but also those that involve conflicts between what is primary and secondary. High levels of construal led individuals to make judgments that were consistent with high-level concerns (the valued goal to study) rather than low-level considerations (e.g., watching TV). As in Experiment 1, this indicates that the effects of construal levels are not reducible to whether one identifies actions in terms of means or ends.

In Experiment 5, to test the hypothesis that high-level construals of a situation lead to decisions and actions that reflect greater self-control, rather than manipulate construal levels through procedural priming in prior unrelated tasks, we directly manipulated participants' construals of self-control conflicts by describing the situation in high-level (abstract, general) terms or low-level (concrete, detailed) terms. We then measured their evaluations of temptations relevant to each scenario. We predicted that describing self-control conflicts in high-level compared with low-level terms would lead to more negative evaluations of temptations.

\section{Experiment 5: Construals of Self-Control Conflicts and Evaluations of Temptations \\ Overview}

Participants were presented with five scenarios, each asking them to imagine themselves in situations involving various self-control conflicts. For half of the participants, these scenarios were described in abstract, general (high-level) terms, whereas for the other half they were described with specific, concrete (low-level) details. Participants were asked to evaluate the temptation in each scenario by indicating how bad they would feel indulging in the temptation. We predicted that participants would report more negative feelings when the conflicts were described in high-level compared with low-level terms.

Method

Participants-Forty-two students (28 women and 14 men) from Tel Aviv University and Open University participated in the study for course credit. They were randomly assigned to either the high-level construal condition or the low-level construal condition.

Procedure-Participants were tested individually by a female experimenter. The experimenter presented a packet with all experimental materials to each participant. They were instructed to imagine themselves in each of five scenarios described in the materials. Each scenario involved a self-control conflict (eating a piece of cake, being lazy and leaving an air conditioner on, copying someone's answer on an exam, going out instead of studying, throwing out gum on the street). To manipulate level of construal, the scenarios were described using only general, abstract terms for half the participants, whereas the scenarios were described with concrete, specific details for the other half. One scenario (translated from Hebrew) is as follows (the wording of the low-level construal condition is in parentheses):

Imagine that you are visiting a friend (at her place, as you both planned ... After you climb the stairs and knock on the door, she opens the door and invites you in ... The room is quite spacious and somewhat orderly, and there is nobody there but the two of you. You are having a pleasant conversation) and she offers you some cake. You are on a diet. You're debating the different possibilities. On the one hand, you won't get fat from eating just one piece of cake. On the other hand, if you eat one piece after another you will eventually get fat. 
After each scenario, participants were asked to indicate their evaluations of the temptation by indicating how bad they would feel if they indulged in it. For example, in the cake scenario, participants were asked, "How bad would you feel if you ate the cake?" Participants responded using a 6-point Likert-type scale, ranging from 1 (not at all bad) to 6 (very $b a d)$. After completing all items, they were then debriefed and dismissed.

\section{Results}

We performed a 2 (level: high vs. low) $\times 5$ (scenario: cake, air conditioner, cheating, going out, and gum) MANOVA on the evaluations of temptations. As anticipated, participants who imagined self-control conflict situations described in high-level terms $(M=3.91, S D=$ 92) reported more negative evaluations of temptations than those for whom the scenarios were described in low-level terms $(M=3.33, S D=.86), F(5,35)=3.18, p=.02, r=.29$.

\section{Discussion}

As in the previous studies, results from Experiment 5 indicated that high-level construals led to greater self-control than low-level construals. In contrast to the previous studies, however, rather than manipulating the tendency to construe situations at high and low levels of construal through procedural priming in an unrelated prior task, in this study we directly manipulated the construal of the self-control conflict. That is, we described situations involving self-control using high-level versus low-level terms and measured participants' evaluations of temptations described in each scenario. As anticipated, describing self-control conflicts in high-level terms led to more negative evaluations than describing them in lowlevel terms. This provides direct support for the hypothesis that construing self-control conflicts at high levels, rather than low levels, leads to decisions and actions that reflect greater self-control.

A potential limitation to this study is that participants in the high-level condition read scenarios that were shorter in length than those in the low-level condition. It is unclear, however, how such differences in length might account for the obtained results. Indeed, longer descriptions might make the self-control conflict more salient, enhancing feelings of potential guilt and regret (a pattern opposite of the results reported previously).

\section{General Discussion}

The studies reported here were designed to test the hypothesis that the activation of highlevel construals versus low-level construals leads to greater self-control. Supporting this hypothesis, in Experiment 1, using an established manipulation of construal levels (Freitas et al., 2004), participants procedurally primed with questions about why they engaged in actions (high-level construal) evidenced reduced preferences for immediate over delayed rewards than those primed with questions about how they engaged in actions (low-level construal). Experiment 2 used a behavioral measure of self-control. For the benefit of receiving self-relevant information, participants exposed to questions of why endured the discomfort of a handgrip longer than those exposed to questions of how. These results were replicated in Experiment $3 \mathrm{~b}$ using a different manipulation of construal levels and measures of behavioral intentions (validated in Experiment 3a). Participants who had generated category labels for a series of objects (high-level construal), compared with those who had generated exemplars (low-level construal), reported stronger intentions to participate in psychological studies that offered high-level benefits with low-level costs. In Experiment 4, participants who had generated category labels evaluated objects associated with temptations that undermine that goal to study less positively than those who generated exemplars. Finally, in Experiment 5, participants who imagined scenarios described in highlevel terms had more negative evaluations of indulging in temptations than those who 
imagined the same scenarios in low-level terms. Across three manipulations of construal level and four dependent measures of self-control, high levels of construal led to greater self-control than low levels of construal.

In addition to documenting the effect of construal levels on self-control, Experiment $3 \mathrm{~b}$ also provided support for the proposed mechanism. We hypothesized that self-control involves making decisions and behaving in a manner consistent with greater weighting of high-level features and concerns over low-level considerations. This suggests that the effects of priming construal levels should be specific to situations that involve a conflict between highlevel and low-level aspects of an activity. Consistent with this suggestion, Experiment $3 \mathrm{~b}$ showed that construal levels affected behavioral intentions only when considerable lowlevel costs (physical discomfort) threatened the attainment of valued high-level benefits (diagnostic self-relevant information).

Because high-level construals weight high-level concerns over low-level concerns in evaluations and decisions, objects and actions associated with temptations (low-level concerns), particularly those that undermine valued high-level concerns, should be evaluated less positively. Supporting this proposal, in Experiment 4, participants at high levels of construal evaluated words associated with temptations that undermine the goal to study less positively than those at low levels. Replicating the results of Experiment 3b, this effect of construal levels was limited to situations involving self-control conflicts. Levels of construal influenced only the evaluation of temptation words and not of all words in general. Also replicating the results of Experiment $3 \mathrm{~b}$, this effect was moderated by the value participants placed on the goal to study. When the goal was valued, high levels led to less positive evaluations of temptations. When it was not valued, high levels had no effect.

In contrast to Experiments 1 through 4, in Experiment 5 we directly manipulated the level of construal by which participants' mentally represented self-control conflicts. That is, rather than procedurally priming the tendency to construe events at high or low levels of construal, we manipulated participants' construals by describing self-control conflicts using abstract, general (high-level) terms or concrete, contextualized (low-level) details and measured how negatively they evaluated indulging in the temptation relevant to each situation. As anticipated, describing self-control conflicts in high-level terms led to more negative evaluations than low-level construals. This direct manipulation of construal provides additional evidence for the postulated process by which high-level construals lead to greater self-control.

The results of the six experiments reported here provide preliminary support for a construallevel analysis of self-control. Shifts in the construal level by which individuals considered a situation had dramatic effects on their self-control decisions and behaviors. Those at a low level of construal became more myopic and motivated by low-level concerns, whereas those at a high level of construal exerted more self-control and acted in accordance to higher level considerations. This suggests that at the core of the self-control problem is the challenge of maintaining the prominence of high-level considerations (those that are global, superordinate, and primary) over low-level concerns (those that are local, incidental, and secondary) in decisions and actions. Individuals who are successfully able to distinguish high- and low-level concerns and maintain the dominance of the high over the low make choices and behave in a manner that reflects self-control. Those who are unable to maintain this distinction make decisions and act in a manner that leads to self-control failure.

\section{Implications for Self-Control}

A construal-level approach has several implications for the study of self-control. For example, any factor that systematically changes levels of construal may affect an 
individual's self-control decisions and actions. For example, research has suggested that positive moods compared with neutral moods lead to more global processing of visual information (Gasper \& Clore, 2002). This suggests that positive moods may enhance selfcontrol through the activation of high-level construals (see Gervey, Igou, \& Trope, in press). Furthermore, engaging in any cognitive procedure that primes high-level construals, such as superordinate categorization, global processing, and abstract or causal reasoning, may lead to greater self-control. In contrast, psychological processes or factors that activate low-level construals, such as attending to the specific, unique characteristics of a situation ("failures of transcendence"; Baumeister \& Heatherton, 1996), perceiving actions as singular acts rather than in the context of behavioral patterns (Rachlin, 1995), should lead to self-control failures.

As stated earlier, a major class of variables that may determine what level of construal is activated is the psychological distance of an event (Liberman et al., in press; Trope \& Liberman, 2003). CLT posits that social stimuli distal on any psychological dimension (time, space, social, hypotheticality) lead to the activation of high-level construals, whereas those that are proximal activate low-level construals. Psychological distance from a selfcontrol situation, therefore, should lead to greater self-control through the activation of highlevel construals. There is some suggestive empirical research, for example, that corroborates with anecdotal evidence that increasing physical distance from stimuli associated with selfcontrol conflicts increases one's ability to exert self-control (Mischel \& Ebbesen, 1970; Vohs \& Heatherton, 2000). Research has also shown that temporal distance leads to systematic reversals of preferences over time, with individuals' preferences related to objects and events in the distant future reflecting greater self-control than those in the near future (e.g., Ainslie \& Haslam, 1992; Frederick et al., 2002; Freitas, Salovey, \& Liberman, 2001). Increasing social distance should also lead to greater self-control. That is, individuals might be expected to advise others to exert self-control in certain situations more than they do themselves. The systematic study of psychological distance promises to be a fruitful new area of self-control research.

Individual differences in the tendency to use high versus low levels of mental representations, such as action identification, may also influence self-control. Research has shown that some individuals (high-level agents) chronically represent their behaviors in high-level terms, whereas others (low-level agents) prefer low-level terms (Vallacher \& Wegner, 1989). There is evidence to suggest that high-level agents may routinely make decisions that reflect greater self-control than low-level agents. For example, Vallacher and Wegner (1989) have shown, using self-report measures, that high-level agents report being less impulsive than low-level agents. Work by Freitas et al. (2001) has also suggested that high-level agents display more self-control when seeking self-relevant information.

\section{Construal-Level Analysis in Relation to Other Models}

We propose a construal-level analysis of self-control as a general theoretical framework that integrates and builds on previously proposed models. The factors that other models propose that enhance self-control are often related to high-level construals, whereas the factors that impair self-control are often associated with low-level construals. For example, factors that undermine self-control such as hot cognitions (Metcalfe \& Mischel, 1999) and visceral reactions (Loewenstein, 1996) are frequently activated by highly salient local, low-level features in one's environment. Cool and more rational thinking, alternatively, allows individuals to transcend and see beyond these affective, appetitive features and, as such, are often linked to more superordinate, high-level concerns. Similarly, unwanted automatic behaviors are often initiated by exposure to concrete, low-level stimuli, whereas controlled behaviors are regularly guided by more global, high-level considerations. The concept of 
construal levels, therefore, incorporates and integrates the factors that other models have proposed as critical variables in self-control conflicts.

A construal-level approach, however, is not synonymous with these other approaches to self-control. Although often highly correlated, low-level construals are not necessarily affective, visceral, short term, and automatic, nor are high-level construals always cool, rational, long term, and controlled. Construal levels allow for both high- and low-level construals to be affective and visceral (vs. cognitive and rational) and automatic (vs. controlled). Moreover, a construal-level analysis can capture self-control conflicts for which time is not an issue. Thus, there are instances when a construal-level analysis generates novel predictions that other models might not. Illustratively, one might consider the problem of the commons or resource-sharing dilemmas. When presented with a shared resource (such as electricity in a power grid), individuals might be tempted to take more than their fair share. If everyone were to do so, however, the shared resource would become immediately unavailable to all parties (causing a sudden and complete blackout). Self-control in such dilemmas, as posited by a construal-level analysis, requires making decisions and acting in accordance with global, high-level considerations (protecting the availability of the resource) and not with local, low-level considerations (maximizing one's share). Any factor that increases the weight of the high-level aspects of the situation (psychological distance, prior activation of high-level construals) should enhance self-control. From the perspective of other models of self-control, it is unclear a priori which of the two options (protecting the resource vs. maximizing one's share) represents an automatic versus controlled behavior, a short-term versus long-term outcome, a hot versus cool mental representation, or a visceral versus rational reaction.

It is important to note that a construal-level analysis is largely mute with respect to egodepletion models of self-control (e.g., Muraven \& Baumeister, 2000). As stated earlier, the ego-depletion model is based on the proposition that exerting self-control consumes a limited self-regulatory resource. A prior exertion of self-control reduces the ability to exert self-control in subsequent activities. Expositions of the ego-depletion model have proposed that self-control involves the inhibition of automatic impulses by more conscious, controlled processes (e.g., Baumeister, Muraven, \& Tice, 2000; Muraven \& Baumeister, 2000). Although a construal-level analysis may incorporate models of self-control that posit similar automatic versus controlled distinctions, it has little to say about the ego-depletion model's core tenet that self-control is a limited resource. Whereas ego-depletion models are concerned with the energy required for self-control, our model focuses on the mental construal of self-control conflicts. It may be that, although high-level construals might increase the tendency for individuals to make decisions that are consistent with self-control concerns, if they are already ego depleted, they may not actually have the energy necessary to carry out or implement those decisions. Likewise, having self-regulatory energy may not lead to greater self-control unless individuals have decided to act on the basis of high-level construals of a situation. Future work, both theoretically and empirically, on integrating the two theoretical approaches is clearly warranted.

In addition to other models of self-control, a construal-level analysis bears resemblance to Vallacher and Wegner's (1987) action identification theory (AIT). Although AIT has not been directly applied to the problem of self-control, it has implications for self-control that are consistent with a construal-level approach. Like CLT, AIT posits that there are high and low levels of mental representation. AIT, however, is a theory of mental representation specific to the representation of actions in hierarchical means-end relationships. Construal levels encompass more than just actions and their means-end relationships. They can represent features of any target: objects, situations, or events. Levels of construal may differ on features beyond means-end relationships, such as whether they refer to primary versus 
secondary goals or to goal-relevant versus goal-irrelevant aspects. For example, in Experiments 1 and 4, levels of construal led to judgments reflecting greater self-control when conflicts existed not between the ends versus means of a particular action but what was primary and secondary. Preferences for immediate over delayed rewards capture a conflict between primary (the value of the reward itself) and secondary (time delay of receipt) features of an object. The conflict of whether to study or socialize with friends and watch TV does not involve a conflict between means and ends but rather a conflict between primary, global and secondary, local goals. Thus, the effect of levels of construal on selfcontrol is not reducible to levels of action identification.

\section{Conclusion}

The present model of self-control posits that self-control involves the preferential activation of high-level construals over low-level construals in decision making and action. We show, consistent with this model, that high-level construals, in comparison to low-level construals, increase self-control. That is, high-level construals allow individuals to maintain the distinction between primary and secondary and to sustain self-control by weighting the high over the low. This construal-level analysis suggests ways of improving self-control that may have important implications for the well-being of individuals and groups.

\section{Acknowledgments}

This research was supported by a National Science Foundation Graduate Student Fellowship, National Institute of Mental Health Grant R01 MH59030-06A1, and United States-Israel Binational Science Foundation Grant 2001057.

We thank Renata Goldsteyn, Miya Kitahara, Nicole Martingano, Bridget Malit, Teresa Nguyen, and Stacey Rimikis for their assistance in data collection and analysis; Antonio Freitas and Ayelet Fishbach for providing us with experimental materials; and Amie Green and Masumi Iida for statistical consultation.

\section{References}

Agrawal, N. Unpublished doctoral dissertation. New York University; 2005. The effects of abstract and concrete construals on outcome bias effects.

Ainslie, G.; Haslam, N. Hyperbolic discounting. In: Loewenstein, G.; Elster, J., editors. Choice over time. New York: Russell Sage Foundation; 1992. p. 57-92.

Bargh JA, Chartrand TL. The unbearable automaticity of being. American Psychologist. 1999; 54:462-479.

Bargh, JA.; Chartrand, T. The mind in the middle: A practical guide to priming and automaticity research. In: Reis, HT.; Judd, CM., editors. Handbook of research methods in social and personality psychology. New York: Cambridge University Press; 2000. p. 253-285.

Baumeister RF, Heatherton TF. Self-regulation failure: An overview. Psychological Inquiry. 1996; 7:1-15.

Baumeister RF, Muraven M, Tice DM. Ego depletion: A resource model of volition, self-regulation, and controlled processing. Social Cognition. 2000; 18:130-150.

Bradley, MM.; Lang, PJ. Affective Norms for English Words (ANEW). Gainesville: University of Florida, NIMH Center for the Study of Emotion and Attention; 1999.

Cohen, J.; Cohen, P.; West, SG.; Aiken, LS. Applied multiple regression/correlation analysis for the behavioral sciences. 3. Mahwah, NJ: Erlbaum; 2003.

Devine PG. Stereotypes and prejudice: Their automatic and controlled components. Journal of Personality and Social Psychology. 1989; 56:5-18.

Fishbach, A. Unpublished manuscript. University of Chicago; 2006. Implicit self-control evaluations.

Förster J, Friedman RS, Liberman N. Temporal construal effects on abstract and concrete thinking: Consequences for insight and creative cognition. Journal of Personality and Social Psychology. 2004; 87:177-189. [PubMed: 15301626] 
Frederick S, Loewenstein G, O’Donoghue T. Time discounting and time preference: A critical review. Journal of Economic Literature. 2002; 40:351-401.

Freitas AL, Gollwitzer PM, Trope Y. The influence of abstract and concrete mindsets on anticipating and guiding others' self-regulatory efforts. Journal of Experimental Social Psychology. 2004; 40:739-752.

Freitas AL, Salovey P, Liberman N. Abstract and concrete self-evaluative goals. Journal of Personality and Social Psychology. 2001; 80:410-412. [PubMed: 11300575]

Gasper K, Clore GL. Attending to the big picture: Mood and global versus local processing of visual information. Psychological Science. 2002; 13:34-40. [PubMed: 11892776]

Gervey B, Igou E, Trope Y. The role of positive mood in pursuing primary self-evaluation goals. Motivation \& Emotion. (in press).

Gilbert DT, Pelham BW, Krull DS. On cognitive busyness: When person perceivers meet persons perceived. Journal of Personality and Social Psychology. 1988; 54:733-740.

Gollwitzer, PM.; Bargh, JA. The psychology of action: Linking cognition and motivation to behavior. New York: Guilford Press; 1996.

Hampson SE, John OP, Goldberg LR. Category breadth and hierarchical structure in personality: Studies of asymmetries in judgments of trait implications. Journal of Personality and Social Psychology. 1986; 51:37-54. [PubMed: 3735069]

Heckhausen, J.; Dweck, CS. Motivation and self-regulation across the life span. New York: Cambridge University Press; 1998.

Higgins, ET.; Kruglanski, AW. Motivational science: Social and personality perspectives. Philadelphia: Psychology Press; 2000.

Keren G, Roelofsma P. Immediacy and certainty in intertemporal choice. Organizational Behavior and Human Decision Processes. 1995; 63:287-297.

Kivetz R, Simonson I. Self-control for the righteous: Toward a theory of precommitment to indulgence. Journal of Consumer Research. 2002; 29:199-217.

Liberman N, Sagristano M, Trope Y. The effect of temporal distance on level of mental construal. Journal of Experimental Social Psychology. 2002; 38:523-534.

Liberman N, Trope Y. The role of feasibility and desirability considerations in near and distant future decisions: A test of temporal construal theory. Journal of Personality and Social Psychology. 1998; 75:5-18.

Liberman, N.; Trope, Y.; Stephan, E. Psychological distance. In: Higgins, ET.; Kruglanski, AW., editors. Social psychology: Handbook of basic principles. Vol. 2. New York: Guilford Press; (in press)

Loewenstein GF. Out of control: Visceral influences on behavior. Organizational Behavior and Human Decision Processes. 1996; 65:272-292.

Metcalfe J, Mischel W. A hot/cool system analysis of delay of gratification: Dynamics of willpower. Psychological Review. 1999; 106:3-19. [PubMed: 10197361]

Mischel W, Ebbesen EB. Attention in delay of gratification. Journal of Personality and Social Psychology. 1970; 16:329-337.

Mischel W, Shoda Y, Rodriguez ML. Delay of gratification in children. Science. 1989 May 26.244:933-938. [PubMed: 2658056]

Muraven M, Baumeister RF. Self-regulation and depletion of limited resources: Does self-control resemble a muscle? Psychological Bulletin. 2000; 126:247-259. [PubMed: 10748642]

Muraven M, Slessareva E. Mechanisms of self-control failure: Motivation and limited resources. Personality and Social Psychology Bulletin. 2003; 29:894-906. [PubMed: 15018677]

Muraven M, Tice DM, Baumeister RF. Self-control as a limited resource: Regulatory depletion patterns. Journal of Personality and Social Psychology. 1998; 74:774-789. [PubMed: 9523419]

Nussbaum S, Trope Y, Liberman N. Creeping dispositionism: The temporal dynamics of behavior prediction. Journal of Personality and Social Psychology. 2003; 84:485-497. [PubMed: 12635911]

Rachlin H. Self-control: Beyond commitment. Behavior and Brain Sciences. 1995; 18:109-159.

Rubenstein A. A theorist's view of experiments. European Economic Review. 2001; 45:615-628. 
Sagristano M, Trope Y, Liberman N. Time-dependent gambling: Odds now, money later. Journal of Experimental Psychology: General. 2002; 131:364-376. [PubMed: 12214752]

Smith ER, Branscombe NR. Procedurally mediated social inferences: The case of category accessibility effects. Journal of Experimental Social Psychology. 1987; 23:361-382.

Sorrentino, RM.; Higgins, ET. Handbook of motivation and cognition: Foundations of social behavior. New York: Guilford Press; 1986.

Thaler, RH. Quasi rational economics. New York: Russell Sage Foundation; 1991.

Trope Y, Fishbach A. Counteractive self-control in overcoming temptation. Journal of Personality and Social Psychology. 2000; 79:493-506. [PubMed: 11045735]

Trope Y, Liberman N. Time-dependent changes in preferences. Journal of Personality and Social Psychology. 2000; 79:876-889. [PubMed: 11138758]

Trope Y, Liberman N. Temporal construal. Psychological Review. 2003; 110:403-421. [PubMed: 12885109]

Vallacher RR, Wegner DM. What do people think they're doing? Action identification and human behavior. Psychological Review. 1987; 94:3-15.

Vallacher RR, Wegner DM. Levels of personal agency: Individual variation in action identification. Journal of Personality and Social Psychology. 1989; 57:660-671.

Vohs K, Heatherton TF. Self-regulatory failure: A resource-depletion approach. Psychological Science. 2000; 11:249-254. [PubMed: 11273412]

Watson D, Clark LA, Tellegen A. Development and validation of brief measures of positive and negative affect: The PANAS scales. Journal of Personality and Social Psychology. 1988; 54:10631070. [PubMed: 3397865]

Wertenbroch K. Consumption self control by rationing purchase quantities of virtue and vice. Marketing Science. 1998; 17:317-337. 


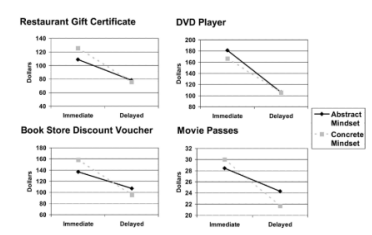

Figure 1.

Dollar values by levels and time (Experiment 1). 


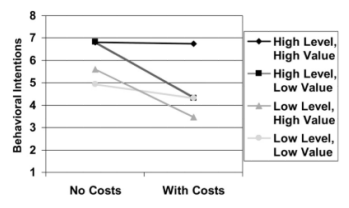

Figure 2.

Behavioral intentions by level, cost, and benefit value (Experiment $3 b$ ). 


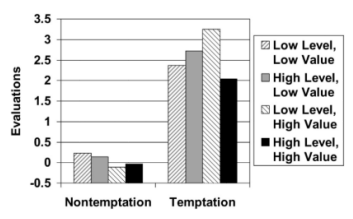

Figure 3.

Evaluations of temptations and nontemptations by level and value (Experiment 4). 


\section{Appendix A}

\section{Experiment 3a Items}

\begin{tabular}{lll}
\hline Item & Low-level & High-level \\
\hline Sweeping the floor & Moving a broom & Being clean \\
Attending a family reunion & Going to a picnic & Respecting tradition \\
Skydiving & Jumping out of an airplane & Demonstrating one's daringness \\
Making an expensive purchase & Swiping a credit card & Doing something for one's pleasure \\
Staying home to study & Reviewing one's notes & Exerting self-discipline \\
Recycling & Bagging paper, glass, and cans & Caring for the environment \\
Teaching & Talking to students & Having authority \\
Meeting new people & Small talk and shaking hands & Enhancing one's social network \\
\hline
\end{tabular}




\section{Appendix B}

\section{Experiment $3 b$ Materials}

\begin{tabular}{|c|c|c|c|}
\hline Study & Benefits & Costs (no costs) & Goal value \\
\hline Health psychology & $\begin{array}{l}\text { Opportunity to consult with } \\
\text { health professional and } \\
\text { review results of } \\
\text { cardiovascular test }\end{array}$ & $\begin{array}{l}\text { Participants have found exercise task } \\
\text { "arduous and difficult" ("easy") and } \\
\text { hormone sampling to be "rather painful" } \\
\text { ("completely painless") }\end{array}$ & $\begin{array}{l}\text { How important is your } \\
\text { physical health to you? }\end{array}$ \\
\hline Cognitive-personality psychology & $\begin{array}{l}\text { Detailed feedback about their } \\
\text { cognitive abilities } \\
\text { (concentration) at night }\end{array}$ & $\begin{array}{l}\text { Participants report having difficulties (no } \\
\text { difficulties) staying awake and feel tired } \\
\text { and sluggish (have no experiences of } \\
\text { feeling sluggish or tired) the following } 2 \\
\text { days }\end{array}$ & $\begin{array}{l}\text { How important is your } \\
\text { ability to concentrate to } \\
\text { you? }\end{array}$ \\
\hline Personal relationships & $\begin{array}{l}\text { Opportunity to review results } \\
\text { of their assessment of } \\
\text { relationship potential }\end{array}$ & $\begin{array}{l}\text { Participants report feeling "very } \\
\text { uncomfortable" ("perfectly } \\
\text { comfortable") answering many of the } \\
\text { personal and intimate questions }\end{array}$ & $\begin{array}{l}\text { How important are } \\
\text { personal and intimate } \\
\text { relationships to you? }\end{array}$ \\
\hline Organizational-workplace psychology & $\begin{array}{l}\text { Receive feedback about their } \\
\text { creativity and their ability to } \\
\text { maintain creativity in adverse } \\
\text { circumstances }\end{array}$ & $\begin{array}{l}\text { White noise at high decibels can be } \\
\text { "painfully irritating" and "jarring" (low } \\
\text { decibels are "painless" and "harmless") }\end{array}$ & $\begin{array}{l}\text { How important is it for } \\
\text { you to be creative? }\end{array}$ \\
\hline
\end{tabular}




\section{Appendix C}

Experiment 4 Stimuli

\begin{tabular}{llll}
\hline Temptations & Positive nontemptations & Neutral nontemptations & Negative nontemptations \\
\hline beer & affection & activate & accident \\
drinking & birthday & appliance & bomb \\
e-mail & bunny & bandage & cockroach \\
internet & diamond & barrel & divorce \\
movie & heal & cliff & germs \\
partying & kiss & fur & mosquito \\
phone & miracle & headlight & pollute \\
socializing & puppy & metal & trash \\
television & rainbow & stool & thief \\
video games & soothe & tease & vomit \\
\hline
\end{tabular}

